\title{
Experiences of Sustainable Abstinence-Based Recovery: an Exploratory Study of Three Recovery Communities (RC) in England
}

\author{
Rebecca Harrison ${ }^{1}$ (D) Marie Claire Van Hout ${ }^{1}$. \\ Madeleine Cochrane ${ }^{2} \cdot$ Lindsay Eckley $^{3}$. \\ Robert Noonan $^{4} \cdot$ Hannah Timpson ${ }^{1} \cdot$ Harry Sumnall ${ }^{1}$
}

Published online: 24 July 2018

(C) The Author(s) 2018

\begin{abstract}
Contemporary recovery-models of treatment for substance misuse prioritise community-based support systems that focus on developing individuals' strengths and quality of life. The research project aimed to explore the perceived mechanisms and processes that underpinned support in three abstinence-based recovery communities (RCs) across England.
\end{abstract}

Rebecca Harrison

R.Harrison@ljmu.ac.uk

Marie Claire Van Hout

M.C.Vanhout@ljmu.ac.uk

Madeleine Cochrane

M.A.Cochrane@2016.ljmu.ac.uk

Lindsay Eckley

L.Eckley@chesterzoo.org

Robert Noonan

Robert.Noonan@edgehill.ac.uk

Hannah Timpson

H.Timpson@ljmu.ac.uk

Harry Sumnall

H.Sumnall@ljmu.ac.uk

1 Public Health Institute, Liverpool John Moores University, Exchange Station (3rd Floor) Tithebarn Street, Liverpool L2 2QP, UK

2 Faculty of Science, School of Sport and Exercise Sciences, Liverpool John Moores University, Great Crosshall Street, Liverpool L3, UK

3 North of England Zoological Society (Chester Zoo), Cedar House, Caughall Road, Chester CH2 $1 \mathrm{EU}, \mathrm{UK}$

4 Edge Hill University, St Helens Road, Ormskirk, Lancashire L39 4QP, UK 
Focus groups and telephone interviews were conducted with 44 individuals. This was to identify self-prioritised outcomes for members and other key factors contributing to the delivery of an effective recovery community. Data were thematically analysed. Along with a number of other key outcomes, the achievement and maintenance of abstinence by participants was considered to be a key indicator of an effective RC. RC processes were also viewed as underpinning the development of recovery capital. The study provides an insight into the processes of RCs and highlights that development and support of recovery capital is an important aspect of service provision and delivery for those in abstinence-based recovery.

Keywords Abstinence-based recovery $\cdot$ Recovery communities $\cdot$ Recovery capital $\cdot$ Social value

\section{Background}

Substance use and dependence is a key public health priority within the United Kingdom (UK). In 2016/2017 there were 279,793 individuals in contact with drug and alcohol treatment services in England and Wales (a decrease of 3\% from 2015 to 16) (Public Health England [PHE] 2017). However, the number of deaths from drug-related poisoning and drug misuse (including legal and illegal substances) in England and Wales in 2016 (3744) is currently at its highest since records began in 1993 (2178) (Office for National Statistics [ONS] 2017). Despite this, the UK Advisory Council on the Misuse of Drugs (ACMD) has noted that funding for drug and alcohol treatment is currently under threat due to reductions in local and national funding (Advisory Council on the Misuse of Drugs [ACMD] 2016). The 2017 UK Drug Strategy highlights the importance of providing services that focus on recovery and the wider support that individuals need to 'achieve and sustain a life free from drugs' (Her Majesty's Government [HM Government] 2017, p.2). This approach utilises the concept of recovery capital to underpin and enhance the quality and quantity of resources available to individuals when initiating and sustaining recovery from problematic substance use (Granfield and Cloud 2001).

Recovery capital refers to the quantity and quality of resources that a person can draw on to initiate and sustain recovery from alcohol and drug dependency and may be seen as critical to successful recovery from substance use (Granfield and Cloud 1999). A key strength of this approach is its consideration of wider social and environmental determinants of health and inequalities that may affect the initiation of recovery, maintenance of long-term abstinence, and achievement of overall treatment outcomes (Granfield and Cloud 2001). Individuals who have a high level of recovery capital are seen to better manage their circumstances and achieve their personal and professional goals, allowing them to reach an optimal quality of life and positively contribute to society (Laudet et al. 2008). A number of key recovery capital domains have been identified that include social (e.g. support networks), physical (e.g. material resources such as money, access to housing and food), human capitals (e.g. well-being, personal assets/skills) (Granfield and Cloud 1999, 2001; Cloud and Granfield 2008; White and Cloud 2008; Neale et al. 2014), and cultural capital (values, beliefs, and identity) (Cloud and Granfield 2004). Timpson et al. (2016) highlight that recovery capital domains may be seen as useful indicators of success. It has, however, been identified that whilst recovery capital has been looked at in numerous studies that focus upon substance use, there is no consistent approach to the use or reporting of recovery capital terms (Hennessey 2017). 
Although there are no normative definitions, recovery has been described by the UK Drug Policy Commission as 'A process of voluntary sustained control over substance use which maximizes health and wellbeing and participation in the rights, roles and responsibilities of society' (UK Drug Policy Commission [UKDPC] 2008, p.6). Successful recovery can be characterised by individuals, families, and communities voluntarily taking control of the drug and alcohol-related problems, and becoming empowered to take on roles and responsibilities that enable them to lead healthy, productive, and meaningful lives (Best et al. 2012; White 2007; UKDPC 2012a, b). It is also acknowledged that recovery is a unique and personal process (Timpson et al. 2016). Aside from individual motivation, behaviour change is dependent on resilience-building motivators such as developing a strong sense of purpose by way of meaningful activities, strengthening supportive social networks, and having access to permanent supportive living accommodation and health care services (Best et al. 2012, 2015b, 2016; Collins et al. 2016). Recovery can promote creation of healthier identities, improvements relationships with family, restore dignity, improve self-acceptance, and increase feelings of community (Irving 2011; Mawson et al. 2015; Wittouck et al. 2013). Positive recovery experiences may also incorporate aspects of spirituality that are associated with well-being, such as gratitude, selfcompassion, and using personal experiences to help others (Kaskutas et al. 2014).

Recovery communities include and involve a fellowship of individuals who are focused upon long-term recovery and abstinence from substance use. A wider recovery community may also be seen to include the family and friends of those in recovery along with professionals who are focused upon addition and recovery (Valentine et al. 2007). These communities organise recovery-focused activities, community education, and outreach programs, as well as providing peer-based recovery support services that focus upon relapse prevention education (Valentine et al. 2007). Strong social networks and self-esteem play an important part in enabling individuals to recognise the significant role they can play in their own recovery (Bracken et al. 2012; Kelly et al. 2009; Tew et al. 2012). It is common for people in recovery to experience distress, face isolation, and limited social support following the loss and erosion of family relationships (Mawson et al. 2015) and loss of previous drug-network friendships (2001; Laudet et al. 2006). Positive social support networks are key to supporting those in recovery (Best et al. 2015a, b; Litt et al. 2009; Stevens et al. 2010; Timpson et al. 2016). High levels of social support are associated with decreased levels of relapse (Granfield and Cloud 2001; Laudet et al. 2006); improved resilience to stress, depression, anxiety, social isolation, and stigma (Best et al. 2015a, b; Hester et al. 2013); enhanced subjective well-being (Laudet et al. 2006); and improved quality of life (Laudet and Stanick 2010; Mericle 2014). Peers and social networks are also integral to the generation of recovery capital (Timpson et al. 2016). Being part of a group and fostering a social identity supports recovery (Best et al. 2010; Buckingham et al. 2013; Kaplan et al. 2010; Pagano et al. 2011, 2013). There is an inverse association between positive peer support networks and recovery relapse (Litt et al. 2009; Moos 2008; Neale and Stevenson 2015; Panebianco et al. 2016; White 2009). Peer support offers opportunities to adopt more positive social norms that can promote engagement in enjoyable non-substance-related activities, and which may override the norms of pro-drug use networks (Laudet et al. 2004; Longabaugh et al. 2010). Peers can also provide diverse forms of emotional and practical support, including financial support, childcare, and a safe place to live (Neale 2001; Neale and Stevenson 2015).

In the UK, peer support models of recovery make up $98 \%$ of mutual aid recovery groups and have gained support in national drugs strategy (HM Government 2017). Despite the increased focus on recovery-based systems, and compared to the USA, UK recovery- 
orientated policies and programs are less developed, and the evidence base supporting their effectiveness in the UK context is limited (Humphreys and Lembke 2014). Unique personal experiences are also inherently difficult to empirically define (Laudet 2007; Knopf 2011; Witbrodt et al. 2015), which presents challenges to establishing key predictors to behaviour change and long-term abstinence, and effective community-based recovery approaches. Further research is therefore required to understand the role of recovery communities in supporting recovery and developing recovery capital.

The study aimed to explore how RCs help individuals to maintain abstinence. This was done by engaging with RC members and key stakeholders to describe the social mechanisms and processes underpinning recovery support for individuals with substance use issues. These RCs were funded by the charity Comic Relief's 'Give it Up' Fund, a programme that ran from 2014 to 2016 and aimed to support the development of RCs in the UK.

\section{Methods}

Ethical approval was granted by the LJMU Research Ethics Committee (reference 14/EHC/ 082). This study utilised interviews and focus groups (FG) with RC members and key service stakeholders between April and July 2015.

The methodological approach was informed by Social Return on Investment (SROI) (The SROI Network 2012) evaluation of these RC as part of a broader social value framework (Social Value International \& Social Value UK 2016). SROI is a framework to assess evidence of value and impact by measuring and accounting for improvements in well-being by incorporating social, environmental, and economic costs and benefits. It also allows for the measurement and capture of outcomes that can be intangible and hard to measure, and is therefore useful for the evidencing of recovery capital outcomes. This method also enables consideration of the wider impacts of community projects on the areas they thrive in. The SROI also identified negative and/or unintended outcomes (these unintended outcomes may be positive or negative). The SROI involved five stages: (1) establishing scope and identifying key stakeholders (scoping activities to analyse and understanding why these have been chosen); (2) mapping outcomes (stakeholder engagement and mapping outcomes); (3) evidencing outcomes and giving them a value; (4) establishing impact (deadweight and attribution); and (5) creating an impact map and calculating the SROI.

The findings of this paper focus specifically upon the qualitative, stakeholder engagement elements of this process. This enabled the researchers to identify and measure different perspectives on the social processes of recovery (Laudet 2007; Knopf 2011; Witbrodt et al. 2015) and the mechanism resulting from the RC, which was brought about this change. This was complimented with a process evaluation that aimed to evidence the experiences and perceptions of key stakeholders involved in delivering the three projects.

Three abstinence-based RCs in central England, south west England, and London took part in the study (Table 1). The RCs were located in areas where indicators such as deaths by drug misuse, hospital stays for alcohol-related harm, and associated indicators such as long-term unemployment and homelessness were higher than the national average (PHE 2016). Each RC differed in setting, size, recovery focus, and delivery due to the history and context in which the RCs were developed. All of the RCs had received large grants funding from the Comic Relief, Give it Up fund to develop specific elements of their RC and these were and the specific elements under evaluation and detailed in this paper. 
Each RC adopted different definitions of abstinence-based recovery. This ranged from guidance on substances that members were or were not permitted to take (for example, the use of antidepressants were excluded from one abstinence policy) to harm reduction approaches for participants at the beginning of their recovery journey, where use of methadone was permitted as part of a opioid dose reduction/discontinuation programme.

Purposive sampling was adopted (Bowling 2002), i.e. participants of the study were purposefully selected with the intention-making generalisations from this sample to the wider $\mathrm{RC}$ population. The evaluation activities being organised in liaison with a gatekeeper at each of the RCs, who provided support in identifying and recruiting key stakeholders and promoting the focus group events, help to maximise the number of attendees.

Focus groups (FG) $(n=6)$ were conducted with 36 individuals attending the three RCs (23 males; 13 females). These were held at a location from which the projects were being delivered. The number of individuals attending each FG ranged from 7 to 13 with a mean attendance of 10 . Across the three RCs, eight telephone interviews were also undertaken with available service stakeholders (staff members [some of whom were also in recovery] and volunteers) (four males/four females). RC members were recruited through a gatekeeper in each site. Verbal informed consent was obtained for service stakeholder interviews, whilst written informed consent was obtained from all taking part in the FG.

The FG guide of questions and probes was designed by the research team and informed from a social value perspective (The SROI Network 2012; Social Value International \& Social Value UK 2016). It focused on gaining an understanding and exploring individual and group reflections around recovery processes, experiences of changes in quality of life, and other personal gains from being part of the RC. FG were conducted at two time points in each site with the second FG (one session of 2-2.5 h) taking place approximately 2 weeks after the first (two, 2-h sessions). The time gap between the FG enabled the researchers to collate the information from the first focus group, reflect and include and details missed, and mark the change in focus from the first to the second FG.

The FG were facilitated by two researchers - one guided the discussion and the second recorded information. The first FG used reflective learning and group discussion to explore and identify individual and group processes and outcomes that were experienced as a result of engaging with the RC. In the second FG, the process of discussion concentrated on identifying a number of key outcomes, placing them in an order (of most to least important) and deciding potential indicators that might be used to evidence these outcomes. The focus groups contributed to the development of a chain of events pathway depicting a common experience of abstinence-based recovery. Whilst it is acknowledged that audio recording can be used to document the group process, due to concerns around intrusiveness and potential effect on FG dynamics and retrieval of information/stifling the openness of the group, FG were not audio recorded. Facilitators recorded handwritten notes throughout, and group post it notes and flipchart information were also taken and used in the analysis.

The process evaluation telephone interviews (semi-structured) with staff and volunteers explored experiences of the implementation of the RCs in each site. Data was gathered regarding understanding of recovery communities, experience of developing and delivering the recovery community, referral processes, and the amount and type of support that was offered. The interviews also elicited perceptions of how the programme was received by service users. Each interview lasted 25-40 $\min ($ mean $=30.7 \mathrm{~min}$ ) and were recorded using a digital recorder. 


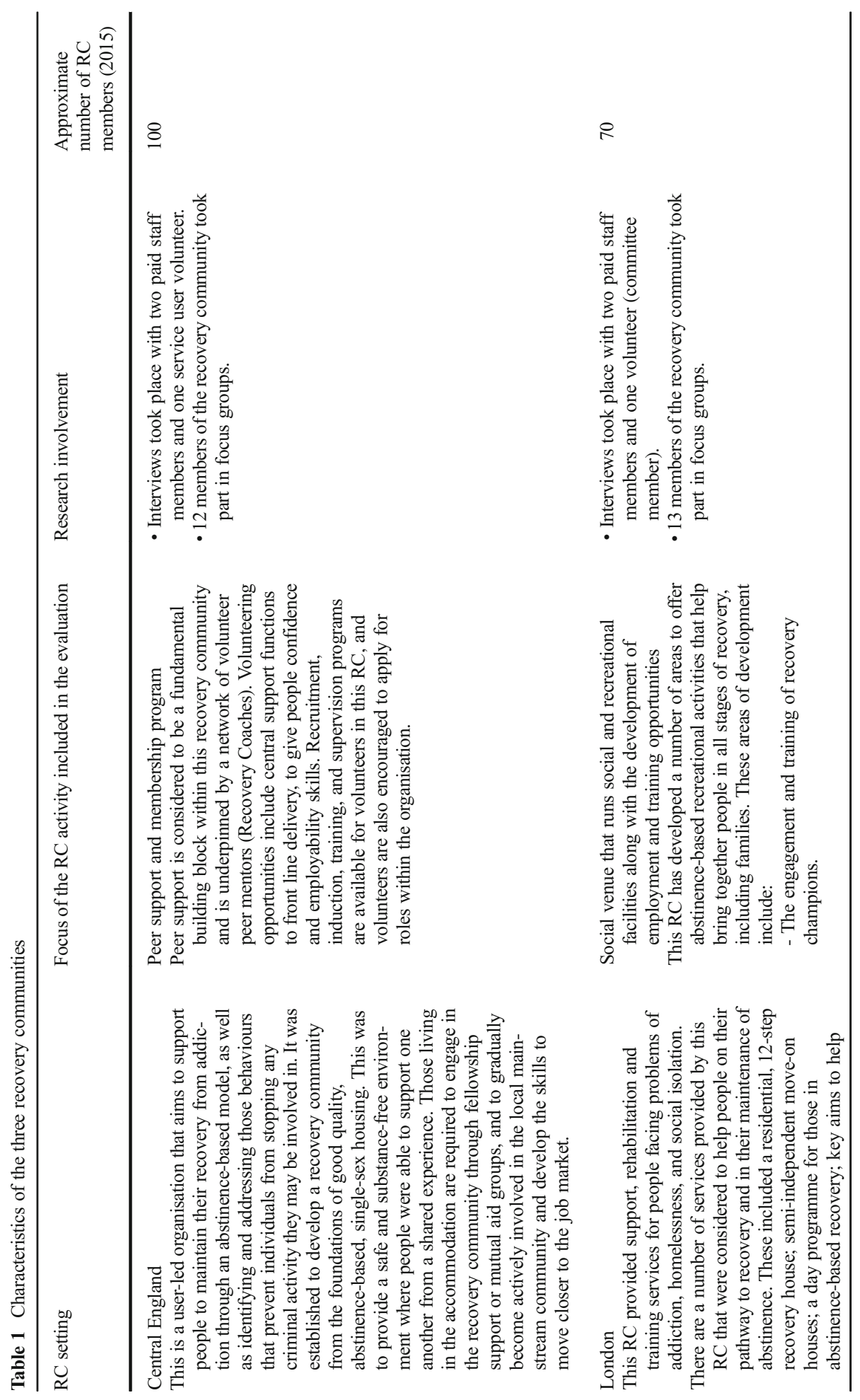




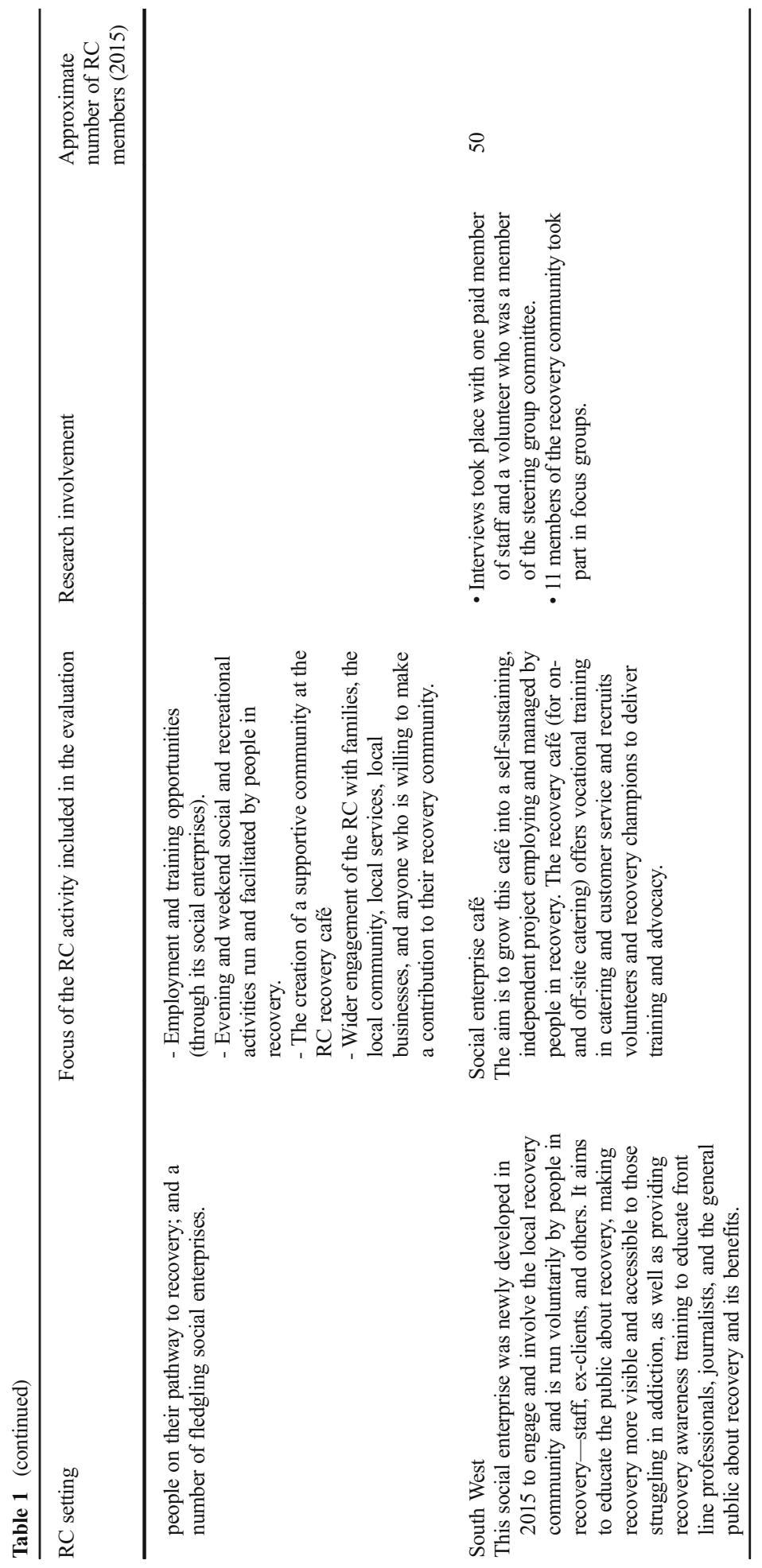


Following transcription of interview recordings, thematic analysis (Stemler 2001; Braun and Clarke 2006) was conducted by two members of the team on the FG and interview data with identified themes being cross-checked and analysed collaboratively. This included familiarisation of data, identifying a thematic framework, indexing, charting, and mapping and interpretation. This process identified a number of key themes: 'supporting the development of recovery capital'; 'person-centred recovery and peer support'; 'reducing stigma'; 'flexible provision of services and connections to education, employment and training'; and 'collaborative working and barriers'.

\section{Results}

\section{How Recovery Communities Support the Development of Abstinence-Based Recovery - the Identification of Outcomes}

The process of developing recovery capital appeared to span across four levels, namely individual, community, relationships, and society, and were evidenced across all three RCs. This is depicted in Fig. 1 and culminated in the identification of four key outcomes. These were sense of purpose and feeling valued, personal capital (e.g. resilience, emotional stability, feeling responsible), improved relationships with family members and friends (family members were additional beneficiaries who experienced positive outcomes as a result of their family member attending the recovery community), and a feeling of being connected or belonging to their RC and wider society. At an individual level, being part of an RC was seen as a journey, a process of discovery, where individuals were encouraged to identify their

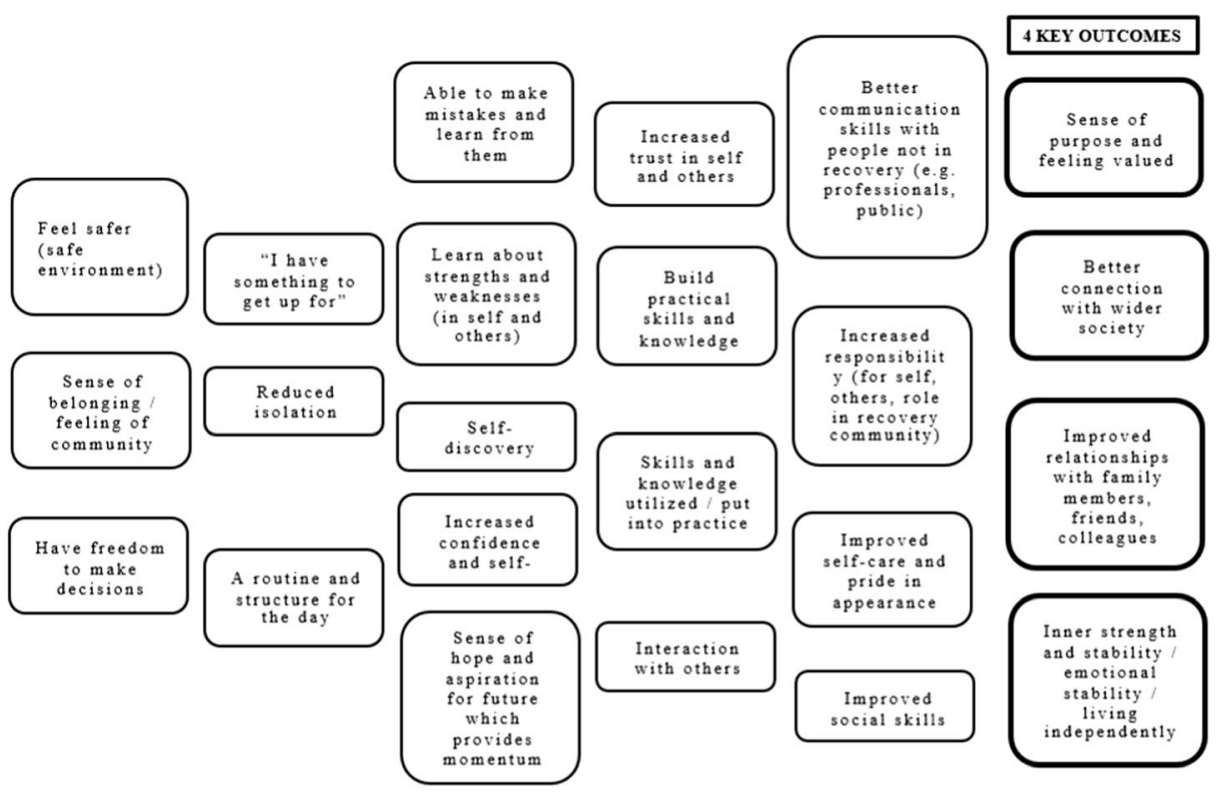

Fig. 1 Chain of events leading to key outcomes experienced by individuals in abstinence-based recovery 
assets as well as their weaknesses in a safe environment. This was thought to enable RC members to build self-confidence and resilience, develop practical skills and knowledge, and to take on responsibilities within the RC itself. Within the RC community, the connection with peers was paramount and tangible in terms of making new friends, building trust, and supporting the development of social skills. Connections and renewed/enhanced relationships with family members were also evident. RC members acquired responsibilities and abilities to re-establish positive relationships with family and friends, and re-building the trust, which in many cases they believed had been lost as a result of their substance use. Connection within society was developed through increased self-confidence, self-esteem, and feelings of selfworth, which led to feelings of equality and reduced social stigma.

Despite the FG having been conducted independently, two of the recovery communities identified the same four key outcomes and prioritised them in the same order: having a sense of purpose and feeling valued, being emotionally able to cope with things, having improved relationships with family members, and feeling better connected with wider society. It was believed by RC members that those without the support of a RC were much less likely to achieve the four outcomes. Participants from one of the RCs described what they believed would happen to them if they did not attend their RC. This included increased isolation, reduced ability to cope, poor health and wellbeing, maintenance of substance use/relapse and associated friendship groups (negative influences), and lack of structure and routine.

\section{Mechanism of Change}

\section{Person-Centred Recovery and Peer Support (Supporting the Development of Social Capital)}

Person-centred approaches to delivery of the RC was seen to provide RC members with options, choice, and holistic support, which engaged and developed the whole person physically, emotionally, mentally, and spiritually. The design and delivery of the RC was underpinned by equity and collaboration between staff, volunteers, and service users. This was considered to be important when considering needs, building relationships, and ensuring the RC itself was culturally and socially appropriate. This approach also helped foster a sense of community, both in terms of individuals having a sense of belonging towards each other and within the physical space and community of the RC. Having fun was described as an important component of recovery support, and one which the recovery communities fostered through interactions with their members, and the offering of activities in a safe and friendly environment.

Peer support was seen to be a key factor of each RC. This was achieved through the development of new, positive social networks not focused on drug use and via RC activities (such as social events and peer support groups). These interacting factors contributed to members developing a strong sense of common purpose and meaning around their roles within the RC and feeling valued for the contribution they provided. Those who were peer mentors were eager to have an opportunity to 'give back' to the community themselves via volunteering, engaging with peers, and actively promoting recovery in the wider public/ professional communities. These roles within the recovery communities provided a foundation for developing confidence and skills in listening, problem-solving, and employability, all viewed as vital for personal progression, maintenance of abstinence, and the recovery journey. 
...it [a support network] is an essential key part, whatever the shape or form the recovery takes ... you have peers and people to spend time with, or construct activities to get involved with ... I don't know anybody that has really managed to sustain a happy and fulfilling life in recovery on their own. (P8: RC3)

Peers who were further along their recovery journey were viewed as role models to newer $\mathrm{RC}$ members. This was seen to provide hope and momentum that abstinence-based recovery is possible and worthwhile, and that there is a 'life beyond addiction'. It was also described as reducing stigma by increasing visibility within and outside of the recovery communities of those in recovery from their substance use issue.

Something that is really important is being around positive people who are doing well in their recovery... because addiction is quite an isolating thing. (P7: RC3)

\section{Reducing Stigma (Supporting the Development of Cultural Capital)}

$\mathrm{RC}$ members considered stigma to be driven by a lack of understanding of addiction, recovery, and the challenges associated with it, both for the general public and those in medical services.

I think one of the main things that stands in the way of recovery is the stigma towards people in recovery, a profound lack of understanding in not only in general in society, also in the medical field as well. There doesn't seem to be enough training and understanding of what addiction is and what is required for recovery. There's the kind of mind-set that people go off for three months go to rehab and get well as if people were going off and trying to mend a broken leg and once that's healed it's ok. That this is an ongoing lifelong challenge for some people and then it can take years to ingrain healthy habits. (P6: RC2)

Two of the RCs responded to this by providing training on addiction and recovery to statutory services such as police and those working in criminal justice, local community groups, and other third sector/voluntary organisations. They also provided a number of opportunities for $\mathrm{RC}$ members to attend educational and training courses and engage in volunteering and mentorship. These opportunities aimed to help members to gain skills and qualifications to prepare for future employment and reintegration into society.

All RCs described projects, events, or training they had established to help members of their $\mathrm{RC}$ interact with the local community exposed them to positive images of recovery. Examples of these projects and events included a voluntary gardening project, family fun days, dog shows, and alcohol-free venue/cafes that were open to those in recovery and their families as well the local community.

Last year we had a family fun day that we organised, we had a dog show, we had games and things like that... There were people there who had nothing to do with [name] or recovery and they came with their dogs for the dog show and had a great time. So it's kind of building that relationship and giving different perspective as well on people that are addicts and are now in recovery. (P8: RC3)

The overall purpose, whilst providing support for those in recovery and their families, was to engage with wider community and those not in recovery to destigmatise recovery and debunk some of the myths around those with substance use issues. Nonetheless, one RC 
described how in their area the recovery agenda was still hidden from the community due to the wider stigma that was attached to recovery and a lack of locally based provision. Two RCs described that by having their recovery community in a visible location, such as on the high street, the public and other businesses were aware and supportive of them, for example, attending events held by the RC and visiting their community cafés. Media platforms were seen as a useful way to increase the visibility of recovery to the local community. These included a magazine, the creation of a film on addiction and recovery, and using social media to engage with the wider community and local businesses. Two RCs described how they developed a social media strategy so they could expand their engagement with service users, as well as businesses on Facebook and Twitter.

\section{Flexible Provision of Services and Connections to Education, Employment, and Training (Supporting the Development of Physical and Human Capital)}

Providing a range of opportunities for RC members was important. The RCs provided access to educational courses and training and enabled RC members to carry out volunteering and mentorship. The flexible delivery of these activities was also important to support ease of attendance. These opportunities aimed to help members to gain skills and qualifications to prepare for future employment and reintegration into society. Participants from two of the RCs described their individually tailored aftercare programme, designed for those who had successfully completed drug detoxification treatment or were abstinent through other means, was distinct from the provision offered by other RCs. This included flexible opening hours such as provision in evenings and providing child friendly support services.

Generally, services are 9-5 so you know, if somebody needed support then, obviously, after 5 o'clock you know, they might struggle. 12-step fellowships have people that will do a 12-step call if somebody is in trouble, but you know, a lot of people won't want to make that call and go 'will you help me?', whereas just coming to a coffee shop they can do, independently without making too much fuss, and there'll be people around who they can have a chat with if they want to. (P7: RC3)

A further example included how opportunities were tailor-made for RC members who were keen to volunteer. Some RC members might have criminal convictions; therefore, completing Disclosure and Barring Service (DBS) checks prior to undertaking regulated volunteer activities with adults and children was sometimes a lengthy process. For these individuals, RCs were able to provide volunteering and educational opportunities where a DBS was not needed, such as gardening, fundraising, marketing, and training courses. In addition, participants in one $\mathrm{RC}$ reported that they were building up a rapport with local businesses that might employ $\mathrm{RC}$ members in future by engaging with them through social media and increasing awareness of what the RC did.

The RCs referred their members to other services including housing providers and counselling services. They also reported having links with local colleges, businesses, and third sector organisations who provided courses and training, some of which were delivered for free. Examples of training and courses included health and social care and social media training, meditation, life drawing, and jewellery making classes. One $\mathrm{RC}$ had links with a theatre and film and a new media company who were helping members to put on a performance to the local community. RC members were also referred internally to, for example, counselling services so that they felt comfortable and safe in familiar surroundings. 
... our artist in resident was here yesterday and he runs an art class on a Monday and something like that it's really simple and straight forward but it's really well attended and it's led onto other things so there's the photography project as well which has now grown out of the photoshoot that we did for the website so there's a lot of potential there. (P3: RC1)

$\mathrm{RC}$ members were seen to be more resilient as a result of engaging with the RCs and described how they were more emotionally able to cope, felt their lives had developed meaning, had improved relationships with family members, and better connections with society.

\section{Strengths and Barriers of Collaborative Working}

The value of the RCs was described by participants as being partly underpinned by freedom and flexibility in their approach to the provision and delivery of their service, and this enabled them to be more responsive to change. Collaborative working was considered to be important in gaining the best possible outcomes for RC members and links were seen to have been made to government-funded services such as housing providers, local colleges, businesses, and third sector organisations. A lack of other abstinence-based service provision was apparent in all three RC sites and members described how tensions sometimes emerged when attempts were made to develop relationships with statutory (and non-statutory) services promoting harm reduction (including opioid substitution treatments) due to differences in focus and approach to recovery. This has implications when looking at how best to integrate recovery community provision into overall substance misuse services.

All RCs emphasised complimentary elements of fellowship and mutual aid, whether that be from attending 12-step (AA, CA, NA), SMART recovery, and were viewed as valuable wraparound support. Individual choice was advocated along with a number of different approaches to mutual aid and individual recovery journeys. Many RC members accessed traditional 12step programs independently of their RC. Despite this, however, all three RCs stated that they found it difficult to develop a reciprocal, working relationship with 12-step programs. This was because the 12-step programs were reluctant to engage with and promote other abstinencebased recovery organisations.

We've got very close links, but it's all very unofficial, just because of their traditions... ,the 12 step fellowships are tricky because they're not affiliated with any other organization, so they have their traditions, and they are very boundaried about how they are seen to be part of anything else. (P7: RC3)

\section{Discussion}

\section{Recovery Community Delivery}

The study provides a valuable contribution to knowledge around recovery outcomes, specific to abstinence-based RCs in England, and what key factors contribute to a 'successful' RC from the perspective of its members and stakeholders. Important delivery factors, which stimulate the success of each RC and the way in which individuals engaged with it, appeared to depend on person-centred recovery approaches, peer support, flexible provision with a tailored needs 
based approach, and wider support (HM Government 2017) through connections to education, employment, and training. These factors central to a successful RC were cross-cutting irrespective of geographical location or service under evaluation. The findings also emphasise the importance of the community setting in providing mutual aid and wrap-around care, which subsequently enables the initiation and maintenance of abstinence-based recovery. Great value was seen in the fact that RCs had freedom in their approach to service provision and delivery and could be responsive to change. Collaborative working was also seen to be important in gaining the best possible outcomes for RC members. Tensions were, however, present when attempting to develop relationships with statutory (and non-statutory) services promoting harm reduction, and the establishment of relationships with 12 steps. This may be due to the differing approaches to achieving and maintaining abstinence, but would benefit from further investigation as to how to best support collaborative working.

\section{The Role of Recovery Capital}

The findings of the research highlighted that $\mathrm{RC}$ members engage with a number of the key domains of recovery capital, namely social, cultural, physical, and human (Granfield and Cloud 1999, 2001; Cloud and Granfield 2004, 2008; White and Cloud 2008; Neale et al. 2014). We know that in general, high levels of recovery capital enable individuals to cope and manage better with their lives (Laudet et al. 2008), which in turn has direct implications for the achievement and maintenance of abstinence.

Social and human capitals (Granfield and Cloud 1999, 2001; Cloud and Granfield 2008; White and Cloud 2008; Neale et al. 2014) were identified to play a crucial role in recovery and were evidenced through members directly engaging in the RC. There is no 'oneapproach fits all' for substance misuse treatment, with the recovery journey seen as a unique and individual process (Timpson et al. 2016) and this was echoed across the RCs. There were, however, shared stories and members believed that the RC provided a nonjudgmental and safe environment that gave them the freedom in which to identify and build upon their assets and develop vital social and practical skills. RCs were seen as a vehicle through which members could become engaged in positive activities to combat social isolation and to support a return to 'normality', both key aspects of the maintenance of abstinence. Members appeared more resilient and developed meaning in their lives evidencing, for example, improved relationships with family members, and better connections with society (Irving 2011; Mawson et al. 2015; Wittouck et al. 2013). The involvement of RC members in problem-solving and decision-making processes was also seen to help the sustainability of recovery communities. Peer support played an important part in the recovery journey. This was achieved through the development of new social networks and engagement in non-substance-related activities (Laudet et al. 2004; Longabaugh et al. 2010) within the communities, so that RC members developed a strong sense of common purpose (Best et al. 2012, 2015a, b, 2016; Collins et al. 2016) and meaning (Cloud and Granfield 2008; Laudet and White 2010). These findings are consistent with other studies that highlight the important role of peers and social networks within the recovery process (Timpson et al. 2016). Such support is pivotal in helping those in recovery to manage their addiction(s) and maintain abstinence (Litt et al. 2009; Stevens et al. 2010). It also provides emotional and practical support (Neale 2001; Neale and Stevenson 2015) and enables individuals to belong to a group, thus fostering social identity (Best et al. 2010; Buckingham et al. 2013; Pagano et al. 2013). 
Aspects of cultural (Cloud and Granfield 2004) and physical (Granfield and Cloud 1999; Cloud and Granfield 2008; White and Cloud 2008) capitals were also evidenced. Stigma is a barrier to recovery, affecting individuals' reintegration into society, for example, their ability to gain employment and access education and training (UKDPC 2008). Cultural capital is important in recovery with those in abstinence being seen to conform to social norms (Cloud and Granfield 2004). Stigma was challenged within the RC by peer mentors as well as through the provision of training on addition and recovery and delivery of and presence at community events, activities which has been evidenced to reduce social and structural level stigma (Livingstone et al. 2012). Recovery communities were also seen to develop physical capital by providing opportunities to attend educational courses and training and carry out mentorship. This helped members identify their assets, develop their skills, and achieve qualifications.

\section{Policy Perspectives}

A key aim of RCs is self-sustainability, which is especially pertinent in current times of reductions in NHS and local authority budgets (ACMD 2017). We are aware anecdotally that currently there is lack of resource within the UK public sector, resulting in increased reliance upon mutual aid groups and RCs such as those described in this study. Many areas across the UK are experiencing an increase in volunteer recovery champions (and this was evidenced in the RCs), but a decrease in salaried front line staff and (expensive) specialists such as addiction psychiatrists.

Local policy in the areas where these RCs were situated shows a focus upon recovery (Durham County Council 2015; Hackney Council 2016; Kilgallon 2013). All three RC in this study, however, highlighted the impact of lack of funding and resources available in their local areas to support those with substance misuse issues to achieve abstinence-based recovery. A reliance upon volunteers and peers, which are inherently not sustainable in the long-term, was also evidence.

In light of these findings, recovery communities such as these have an important role to play, especially in areas where local authorities have limited budgets to provide structured treatment. RCs are individually and collectively community asset that warrant support and expansion, and are equally made up of individual assets, which collectively support the powerful mechanisms in generating recovery capital.

\section{Limitations}

The study provided localised views around RC implementation and recovery capital processes and so cannot be generalizable. Limitations of the study centre on its restriction to three RC sites, potential for gatekeeper bias, and the inability to compare responses on the basis of factors such as gender- and age-related perspectives.

\section{Conclusion}

The study provides a unique insight into the processes of RCs, and the multiplicity of factors affecting and supporting the development of recovery capital. It adds to the evidence that RCs play a vital role in abstinence-based models for recovery and should be integrated into statutory service provision. Even though the RCs here used different approaches to delivery of support and the activities they engage, they are underlined by similar factors - strengthening recovery capital, 
peer support, community setting, holistic, and flexible support/experiences. The way in which these are provided is tailored to the political and geographical context in which they are situated. Thus, recovery journeys become a community experience that reinforces the maintenance of abstinence and this may be why overarching, shared outcomes are experienced.

Development and support of recovery capital offers a key inroad to inform future service provision and delivery for those in abstinence-based recovery across the UK. Further research and $\mathrm{RC}$ evaluations are warranted, possibly into the sustainability of RCs as a mechanism to recovery, to inform the area.

Authors' Contribution RH contributed to study design, conducted data collection and analysis, and wrote the paper. MCVH provided feedback and substantive editorial contribution to the written paper. MC conducted data collection and analysis and gave feedback on paper drafts. LE designed the study, conducted data collection and analysis, and gave feedback on paper drafts. RN updated the literature review and gave feedback on paper drafts. HT contributed to the design of the study and provided feedback on paper drafts. HS contributed to the design of the study and provided feedback on paper drafts.FundingThis work was supported by Comic Relief under the Give it Up Fund.

\section{Compliance with Ethical Standards}

Conflict of Interest The authors report no conflicts of interest. The authors alone are responsible for the content and writing of this article.

Open Access This article is distributed under the terms of the Creative Commons Attribution 4.0 International License (http://creativecommons.org/licenses/by/4.0/), which permits unrestricted use, distribution, and reproduction in any medium, provided you give appropriate credit to the original author(s) and the source, provide a link to the Creative Commons license, and indicate if changes were made.

\section{References}

ACMD (Advisory Council on the Misuse of Drugs). (2016). Reducing opioid-related deaths in the UK. Retrieved from: https:/www.gov.uk/government/uploads/system/uploads/attachment_data/file/576560 /ACMD-Drug-Related-Deaths-Report-161212.pdf [Accessed 20th February 2018].

ACMD (Advisory Council on the Misuse of Drugs) (2017). Commissioning impact on drug treatment. Retrieved from: https://www.gov.uk/government/publications/commissioning-impact-on-drug-treatment [Accessed 2nd March 2018].

Best, D., Rome, A., Hanning, K., White, W., Gossop, M., Taylor, A., \& Perkins, A. (2010). Research for recovery: A review of the drugs evidence base, crime and justice social research, Scottish Government. Edinburgh: Scottish Government.

Best, D., Gow, J., Knox, T., Taylor, A., Groshkova, T., \& White, W. (2012). Mapping the recovery stories of drinkers and drug users in Glasgow: quality of life and its associations with measures of recovery capital. Drug Alcohol Review, 31, 334-341. https://doi.org/10.1111/j.1465-3362.2011.00321.x.

Best, D., Beckwith, M., Haslam, C., Haslam, S. A., Jetten, J., Mawson, E., \& Lubman, D. I. (2015a). Overcoming alcohol and other drug addiction as a process of social identity transition: the social identity model of recovery (SIMOR). Addiction Research \& Theory, 24(2), 111-123. https://doi.org/10.3109 $/ 16066359.2015 .1075980$.

Best, D., McKitterick, T., Beswick, T., \& Savic, M. (2015b). Recovery capital and social networks among people in treatment and among those in recovery in York, England. Alcoholism Treatment Quarterly, 33, $270-282$. https://doi.org/10.1080/07347324.2015.1050931.

Best, D., Beswick, T., Hodgkins, S., \& Idle, M. (2016). Recovery, ambitions, and aspirations: an exploratory project to build a recovery community by generating a skilled recovery workforce. Alcoholism Treatment Quarterly, 34(1), 3-14. https://doi.org/10.1080/07347324.2016.1113105.

Bowling, A. (2002). Research methods in health. Investigating health and health services (2nd ed.). Buckingham: Open University Press. 
Bracken, P., Thomas, P., Timimi, S., Asen, E., Behr, G., Beuster, C, et al. (2012). Psychiatry beyond the current paradigm. British Journal of Psychiatry, 201, 430-434. https://doi.org/10.1192/bjp.bp.112.109447.

Braun, V., \& Clarke, V. (2006). Using thematic analysis in psychology. Qualitative Research Psychology, 3, 77101. https://doi.org/10.1191/1478088706qp063oa.

Buckingham, S., Frings, D., \& Albery, I. P. (2013). Group membership and social identity in addiction recovery. Psychology of Addictive Behaviors, 27(4), 1132-1140. https://doi.org/10.1037/a0032480.

Cloud, W. \& Granfield, R. (2004). A life course perspective on exiting addiction: The relevance of recovery capital in treatment. Publication no. 44. NAD Publication; p. 185-202.

Cloud, W., \& Granfield, R. (2008). Natural recovery from dependency. Journal of Social Work Practice in the Addictions, 1(1), 83-104. https://doi.org/10.1300/J160v01n01_07.

Collins, S. E., Jones, C. B., Hoffmann, G., Nelson, L. A., Hawes, S. M., Grazioli, V. S., Mackelprang, J. L., Holttum, J., Kaese, G., Lenert, J., Herndon, P., \& Clifasefi, S. L. (2016). In their own words: content analysis of pathways to recovery among individuals with the lived experience of homelessness and alcohol use disorders. International Journal of Drug Policy, 27, 89-96. https://doi.org/10.1016/j.drugpo.2015.08.003.

Durham County Council (2015). Drug and alcohol review briefing note four. Retrieved from: http://www. durham.gov.uk/media/5885/Drug-and-Alcohol-Review-Briefing-Note-Four/pdf/DrugAndAlcoholReviewBriefingNote4.pdf [Accessed 20th February 2018].

Granfield, R., \& Cloud, W. (1999). Coming clean: Overcoming addiction without treatment. New York: New York University Press.

Granfield, R., \& Cloud, W. (2001). Social context and "natural recovery": the role of social capital in the resolution of drug-associated problems. Substance Use \& Misuse, 36(11), 1543-1570. https://doi. org/10.1081/JA-100106963.

Hackney Council. (2016). City and hackney joint strategic needs assessment: Mental health and substance misuse. Retrieved from: http://www.hackney.gov.uk/jsna [Accessed 20th February 2018].

Hennessey, E. (2017). Recovery capital: a systematic review of the literature. Addiction Research \& Theory, 25(5), 349-360. https://doi.org/10.1080/16066359.2017.1297990.

Her Majesty's (HM) Government. (2017). 2017 drug strategy. Retrieved from: https://www.gov. uk/government/uploads/system/uploads/attachment_data/file/628148/Drug_strategy_2017.PDF [Accessed 20th February 2018].

Hester, R. K., Lenberg, K. L., Campbell, W., \& Delaney, H. D. (2013). Overcoming addictions, a web-based application, and SMART recovery, an online and in-person mutual help Group for Problem Drinkers, part 1: three- month outcomes of a randomized controlled trial. Journal Medical Internet Research, 15(7), e134. https://doi.org/10.2196/jmir.2565.

Humphreys, K., \& Lembke, A. (2014). Recovery-oriented policy and care systems in the UK and USA. Drug and Alcohol Review, 33, 13-18. https://doi.org/10.1111/dar.12092.

Irving, A. (2011). Life story narratives of recovery from dependent drug and alcohol use: a tool for identity reconstruction within a therapeutic community. Therapeutic Communities, 32(3), 182-200.

Kaplan, L., Nugent, C., Baker, M., Clark, H. W., \& Veysey, B. M. (2010). Introduction: the recovery community services program. Alcoholism Treatment Quarterly, 28(3), 244-255. https://doi.org/10.1080 /07347324.2010.488522.

Kaskutas, L. A., Borkman, T. J., Laudet, A., Ritter, L. A., Witbrodt, W., Subbaraman, M. S., Stunz, A., \& Bond, J. (2014). Elements that define recovery: the experiential perspective. Journal of Studies on Alcohol and Drugs, 75(6), 999-1010.

Kelly, J. F., Magill, M., \& Stout, R. L. (2009). How do people recover from alcohol dependence? A systematic review of the research on mechanisms of behaviour change in alcoholics anonymous. Addiction Research and Theory, 17(3), 236-259. https://doi.org/10.1080/16066350902770458.

Kilgallon, R. (2013). Public Health Birmingham drugs and alcohol needs assessment 2013/2014. Birmingham: Birmingham City Council.

Knopf, A. (2011). Definition of recovery is vague, measures elusive, even as taxpayers fund services. Alcoholism and Drug Abuse Weekly, 23(18).

Laudet, A. B. (2007). What does recovery mean to you? Lessons from the recovery experience for research and practice. Journal of Substance Abuse and Treatment, 33(3), 243-256.

Laudet, A. B., \& Stanick, V. (2010). Predictors of motivation for abstinence at the end of outpatient substance abuse treatment. Journal of Substance Abuse Treatment, 38, 317-327. https://doi.org/10.1016/j. jsat.2010.01.007.

Laudet, A., \& White, W. (2010). What are your priorities right now? Identifying service needs across recovery stages to inform service development. Journal of Substance Abuse Treatment, 38(1), 51-59. https://oi. org/10.1016/j.jsat.2009.06.003. 
Laudet, A. B., Cleland, C. M., Magura, S., Vogel, H. S., \& Knight, E. L. (2004). Social support mediates the effects of dual-focus mutual-aid groups on abstinence from substance use. American Journal of Community Psychology, 43, 175-185. https://doi.org/10.1007/s10464-004-7413-5.

Laudet, A. B., Morgen, K., \& White, A. L. (2006). The role of social supports, spirituality, religiousness, life meaning and affiliation with 12-step fellowships in quality of life satisfaction among individuals in recovery from alcohol and drug problems. Alcohol Treatment Quarterly, 24(1-2), 33-73. https://doi.org/10.1300/J020 v24n01 04.

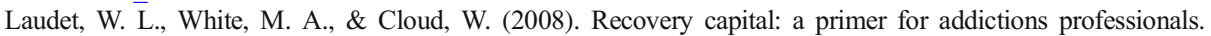
Counselor, 9(5), 22-27.

Litt, M. D., Kadden, R. M., Kabela-Cormier, E., \& Petry, N. M. (2009). Changing network support for drinking: network support project two-year follow-up. Journal of Consulting and Clinical Psychology, 77(2), 229242. https://doi.org/10.1037/a0015252.

Livingstone, J. D., Milne, T., Fang, M. L., \& Amari, E. (2012). The effectiveness of interventions for reducing stigma related to substance use disorders: a systematic review. Addiction, 107(1), 39-50. https://doi. org/10.1111/j.1360-0443.2011.03601.x.

Longabaugh, R., Wirtz, P. W., Zywiak, W. H., \& O’Malley, S. S. (2010). Network support as a prognostic indicator of drinking outcomes: the COMBINE study. Journal of Studies on Alcohol and Drugs, 71, 837-846.

Mawson, E., Best, D., Beckwith, M., Dingle, G. A., \& Lubman, D. I. (2015). Social identity, social networks and recovery capital in emerging adulthood: a pilot study. Substance Abuse Treatment, Prevention, and Policy, 10(45), 45. https://doi.org/10.1186/s13011-015-0041-2.

Mericle, A. A. (2014). The role of social networks in recovery from alcohol and drug abuse. The American Journal of Drug and Alcohol Abuse, 40(3), 179-180. https://doi.org/10.3109/00952990.2013.875553.

Moos, R. H. (2008). Active ingredients of substance use-focused self-help groups. Addiction, 103(3), 387-396. https://doi.org/10.1111/j.1360-0443.2007.02111.x.

Neale, J. (2001). Drug users in society. Basingstoke: Palgrave MacMillan.

Neale, J., \& Stevenson, C. (2015). Social and recovery capital amongst homeless hostel residents who use drugs and alcohol. International Journal of Drug Policy, 26, 475-483. https://doi.org/10.1016/j. drugpo.2014.09.012.

Neale, J., Nettleton, S., \& Pickering, L. (2014). Gender sameness and difference in recovery from heroin dependence: a qualitative exploration. The International Journal on Drug Policy, 25, 3-12. https://doi. org/10.1016/j.drugpo.2013.08.002.

Office for National Statistics (ONS) (2017). Deaths related to drug poisoning in England and Wales: 2016 registrations. Retrieved from: https://www.ons.gov.uk/peoplepopulationandcommunity/birthsdeathsandmarriages/deaths/bulletins/deathsrelatedtodrugpoisoninginenglandandwales/2016 registrations [Accessed 20th February 2018].

Pagano, M. E., Post, S. G., \& Johnson, S. M. (2011). Alcoholics anonymous-related helping and the helper therapy principle. Alcoholism Treatment Quarterly, 29(1), 23-34. https://doi.org/10.1080 /07347324.2011.538320.

Pagano, M. E., White, W. L., Kelly, J. F., Stout, R. L., \& Tonigan, J. S. (2013). The 10-year course of alcoholics anonymous participation and long-term outcomes: a follow-up study of outpatient subjects in project MATCH. Substance Abuse, 34(1), 51-59. https://doi.org/10.1080/08897077.2012.691450.

Panebianco, D., Gallupe, O., Carrington, P. J., \& Colozzi, I. (2016). Personal support networks, social capital, and risk of relapse among individuals treated for substance use issues. International Journal of Drug Policy, 27, 146-153. https://doi.org/10.1016/j.drugpo.2015.09.009.

Public Health England (PHE). (2016). Birmingham: Health Profile 2016. Retrieved from: http://fingertips.phe. org.uk/profile/health-profiles [Accessed 20th February2018].

Public Health England (PHE). (2017). Adult substance misuse statistics from the National Drug Treatment Monitoring System (NDTMS). 1st April to 31 March 2017. Retrieved from: https://www.gov. uk/government/uploads/system/uploads/attachment_data/file/658056/Adult-statistics-from-the-nationaldrug-treatment-monitoring-system-2016-2017.pdf. [Accessed 21st February 2018].

Social Value International and Social Value UK (2016). Understanding and use of the principles of social value. Available from: http://socialvalueint.org/wp-content/uploads/2017/04/Understanding-and-Use-of-ThePrinciples-of-Social-Value.pdf [Accessed 20th December 2017]

SROI Network. (2012). The guide to social return on investment. Available from: http://socialvalueuk. org/publications/publications/cat_view/29-the-guide-to-social-return-on-investment [Accessed 20th February, 2018].

Stemler, S. (2001). An overview of content analysis. Practical Assessment, Research \& Evaluation, 7(17). Retrieved from: http://pareonline.net/getvn.asp?v=7\&n=17 [Accessed 20th February 2018].

Stevens, E. B., Jason, L. A., Ferrari, J. R., \& Hunter, B. (2010). Self-efficacy and sense of community among adults recovering from substance abuse. North American Journal of Psychology, 12(2), 255-264. 
Tew, J., Ramon, S., Slade, M., Bird, V., Melton, J., \& Le Boutillier, C. (2012). Social factors and recovery from mental health difficulties: a review of the evidence. British Journal of Social Work, 42, 443-460. https://doi. org/10.1093/bjsw/bcr076.

Timpson, H., Eckley, L., Sumnall, H., Pendlebury, M., \& Hay, G. (2016). Once you've been there, you're always recovering: exploring experiences, outcomes, and benefits of substance misuse recovery. Drugs and Alcohol Today, 16(1), 29-38. https://doi.org/10.1108/DAT-08-2015-0042.

UK Drug Policy Commission (UKDPC). (2008). The UK drug policy commission recovery consensus group. A vision of recovery. Retrieved from: http:/www.ukdpc.org.uk/wp-content/uploads/Policy\%20report\%20-\%20 A\%20vision\%20of\%20recovery_\%20UKDPC\%20recovery\%20consensus\%20group.pdf [Accessed 2nd March 2018].

UK Drug Policy Commission (UKDPC). (2012a). A fresh approach to drugs. Final report of the UK Drug Policy Commission. Retrieved from: http://www.ukdpc.org.uk/wp-content/uploads/a-fresh-approach-todrugs-the-final-report-of-the-uk-drug-policy-commission.pdf [Accessed 2nd March 2018].

UK Drug Policy Commission (UKDPC). (2012b). The forgotten carers: Support for adult family members affected by a relative's drug problems. London: UK Drug Policy Commission. Retrieved from: http://www. ukdpc.org.uk/publication/the-forgotten-carers/ [Accessed 2nd March 2018].

Valentine, P., White, W. \& Taylor, P. (2007). The recovery community organization: Toward a working definition and description. Retrieved from: http://www.williamwhitepapers.com/pr/2007 DefiningRecoveryCommunityOrganization.pdf [Accessed 2nd March 2018].

White, W. (2007). The new recovery advocacy movement in America. Addiction, 102, 696-703. https://oi. org/10.1111/j.1360-0443.2007.01808.x.

White, W. (2009). The mobilisation of community resources to support long-term addiction recovery. Journal of Substance Abuse Treatment, 36, 146-158. https://doi.org/10.1016/j.jsat.2008.10.006.

White, W \& Cloud, W (2008). Recovery capital: A primer for addictions professionals. Counsellor, 9(5), 22-27. Available from: http://www.williamwhitepapers.com/pr/2008RecoveryCapitalPrimer.pdf [Accessed 19th July 2018].

Witbrodt, J., Kaskutas, L. A., \& Grella, C. E. (2015). How do recovery definitions distinguish recovering individuals? Five typologies. Drug and Alcohol Dependence, 148(1), 109-117. https://doi.org/10.1016/j. drugalcdep.2014.12.036.

Wittouck, C., Dekkers, A., De Ruyver, B., Vanderplasschen, W., \& Vander Laenen, F. (2013). The impact of drug treatment courts on recovery: a systematic review. The Scientific World Journal, 2013, 1-12. https://doi. org/10.1155/2013/493679. 